\title{
All Quiet on the Neoliberal Front? A Reconsideration of Habermas's Legitimation Crisis
}

\author{
Sascha Engel
}

\section{Introduction}

This paper explores why capitalism, while certainly in the throes of a systemic crisis of advanced industrial allocation precipitated by financial tumult, is not in the midst of a corresponding crisis of legitimation. I proceed from the assumption that one can currently diagnose several economic and political crisis - mainly the Great Recession since 2008 and the European sovereign debt crisis since 2010. Furthermore, it appears that movements such as Occupy do indeed question the normative foundations of capitalism in these crises. I aim to explore reasons, then, for the peculiar constellation that this combination of objective crisis conditions and corresponding normative critique does not result in widespread crises of the legitimation of capitalist economies and market-guaranteeing nation-states.

Thus, the paper positions itself within the space of a question posed by a variety of contemporary observers. There is a widespread unease among professional social critics regarding the virtues of an economic system that, in Joseph Stiglitz's words, "is seen to fail for most citizens" (Stiglitz 2006: XII) and that consequently seems to make it a necessity to question both its efficiency and its moral foundations (ibid.: XI and XIII). Similar arguments abound in the recent literature (cf., for example, Skidelsky 2010; Rodrik 2011; Harvey 2011; Fraser 2012). Habermas's (2011) own work on the crisis of the European Union and even the European project under conditions of economic crisis is a case in point. It appears abundantly clear that the current socio-economic configuration of financial capitalism is in a crisis of economic performance. This crisis manifests itself not only on the demand side, where U.S. and European consumption remains threatened by wide margins of inequality and a corresponding lack of effective demand (cf., for the U.S., Galbraith 2012: 293; for Europe: Shambaugh 2012: 169). The supply side of U.S. and European economies is likewise affected by credit conditions which, despite five years having passed since the outbreak of the Subprime Crisis, still remain fragile (for Europe, this is analyzed in Shambaugh 2012; for the U.S., in Reinhart and Rogoff 2012). In addition to this, some have argued for social movements like the Alterglobalization movement or Occupy to be interpreted as a Habermasian project of reengaging a legitimation crisis (see, for example, Bornstein 2009: 102 sq.). Yet, despite these criticisms, neither the global financial economy, nor its national varieties in Europe or the United States, nor even the underlying exploitative relations they project and sustain, are subject to widespread public normative questioning. In his most recent work, Philip Mirowski (2013) notes this as well: while the economic system seemed to be in shambles in 2008 and 2009, and its most stalwart defenders had either turned into humble apologetics of state intervention, or seemed to be brushed to the wayside if they continued to toot the horn of economic orthodoxy, the presumption that it was high time to pit new ideas against old ones, and sustain the normative critique of global financialized capitalism until its legitimation evaporated, "was itself just one more insidious hallucination" (Mirowksi 2013: 1).

My focus differs from Mirowski in that I explicitly address not the role of economic discourse in engendering and exacerbating the crisis, but rather its opposing discourse: possible sources of its normative questioning (or the 
absence thereof). To this end, I introduce an analysis based on Jürgen Habermas's Legitimation Crisis (1975). Thus, I argue for a theoretical perspective departing, first, from Jürgen Habermas's assumption that the legitimation of any social set of institutions is necessary for the continuous survival of these institutions. In Legitimation Crisis itself, Habermas applied this perspective to a historically specific combination of capitalist markets and market-guaranteeing, but also welfare-oriented nation-states which had since been replaced with a different, financialized configuration. As I will show in this paper, however, Habermas's argument is embedded in a more systematic perspective which sheds light on why the legitimation of any such configuration of capitalist markets and market-guaranteeing nation-states is threatened by their underperformance under conditions of economic crises. The origin of the possibility of this transposition of economic crises of performance to normative crises of legitimation of capitalism, for Habermas, is the dual nature of all social interaction, which is at once aligned by non-normative mediations (through money, laws, power, etc.) and open to intersubjective scrutiny. Embedding this latter element in a historical trajectory leading from the crisis patterns of the 1970s, through the neoliberal project - defined here, with Harvey (2005), as the totality of political, social, and economic measures encompassing, among others, deregulation of financial markets, reorganization of labor patterns toward flexibility and precarious employment, the reorganization of states towards authoritarian free-market pseudo-democracies, the abolition of welfare measures, etc. - allows, I argue, a diagnosis of the origins of today's absence of widespread normative questioning of capitalism.

Thus, invoking Habermas's categories is not merely an exegetical endeavor in updating his theory. Rather, using Habermas's theory as a starting point for the analysis of the conditions which make a transposition of economicfunctional crises into political-normative crises allows to trace changes these conditions of possibility have undergone since Habermas's writing. As mentioned above, one can diagnose the objective persistence of several economic crises of (potentially) global ramifications, along with the existence of movements questioning the normative foundations of the economic system in crisis. The latter suggests, as I will argue, that claims of a suppression of the politicality of the current economic crises by media discourses are misguided. Rather, I maintain that the neoliberal project has severely threatened the ability of subjects in Western capitalist societies to withdraw their normative support to, and hence engender a legitimation crisis of the capitalist system in its current form.

In the second and third sections of this paper, I engage Habermas's theoretical framework and its central argument - the opposition between a lifeworld as a reservoir for normative judgments on the one hand, and systemic dynamics continually working to emancipate themselves from this normative reservoir and the judgments it engenders, on the other. Despite Habermas's crisis theory being contained mainly in his Legitimation Crisis, it is useful to approach the central concepts explaining the origin of legitimation, both as a normative question and as a systemic resource, based on what Habermas himself identified as their more systematic exposition in the Theory of Communicative Action (1989: 344). This will allow an exploration, in section four, as to possible reasons for its inapplicability to contemporary economic crisis conditions.

\section{System and Lifeworld}

Crises of economic performance appear to be a necessary part of the cycles of capitalist accumulation. For David Harvey (2011: 11), economic crises are necessary occurrences in the processes of capitalist accumulation because they serve to rationalize over- and undershoots of economic allocation. This process itself, however, is irrational and includes the squandering of productive capacities and livelihoods. Thus, as Stiglitz (2006: XII) points out, this rationalization of productive and pricing processes by way of economic crisis is normatively highly questionable: the simultaneous existence of empty homes and homeless people in the Great Recession, for example, certainly seems to be problematic.

It is this normative questioning that Habermas argued for. The structure of Stiglitz's argument - an argument that can be found in numerous other recent works, such as Minsky (2008) as well - poses the question of a capitalist system that appears to have emancipated its social dynamic from moral and normative foundations. As pointed out in the introduction, Habermas's theoretical framework would appear to allow for the continued possibility of normative critique despite these anti-normative dynamics.

According to Habermas, every social institution is perceived from two different angles by subjects relating to these institutions. As Stephen White (1980: 1008) explains, these perceptions always contain a normative component. This component's central stake is a normative deliberation among subjects regarding the legitimacy of the social 
institutions they come to be governed by. A normative deliberation of this kind is possible, according to White's explication of Habermas's theory, because it takes place in a "discourse [which] is freed from formal constraints on the process of argumentation itself, as well as constraints which are brought into that process from the surrounding context of interaction" (ibid.: 1009). Such constraints are the second angle, then: functional dynamics draining subject's interactions of normative potential by imposing on it the very forms of communicative rationalities prescribed by the institutions to be assessed. If a communicative interaction between subjects is modulated by such contextual constraints, these subjects act according to the systemic aspect of the communicative interaction. If it is not, normative judgments are possible: subjects view the interaction from the perspective of a lifeworld (Habermas 1989: 118).

The first element of this theory to be considered is its ontology. Institutions, for Habermas, consist of social interactions which are aligned by way of systemic dynamics. They therefore arise out of specific social regions Habermas (1989: 150) calls "subsystems," but need not be thoroughly associated with them: an institution like a company arises out of the economic subsystem, insofar as its profit-maximizing goal is concerned, but it can also be seen from a legal perspective or, normatively, from a political perspective. Thus, every institution can analytically be resolved into distinct interactions, which, in turn, contain subjects aligned according to the systemic medium the interaction is aligned by, as well as normative judgments by these subjects, but independent of systemic media. Habermas (ibid.: 117) calls such socially aligned situational subjectivities "action orientations."

Secondly, however, it is imperative to understand how subsystemic constraints operate and of what they are constraints. Subsystems are social regions organized by mediations: they consist of communicative routines governing human interactions (Habermas 1989: 154). Thus, in each interaction, a subject is constituted by the communicative position it occupies. For example, if a subject actualizes the juridical subsystem, she will interpret her surroundings according to the parameters of coding reality in terms of lawful/unlawful (as well as other, perhaps more nuanced oppositions). Likewise, in an interaction mediated by the economic subsystem, a subject will assume a position structured by the institutional routines of wage labor, coding her reality in terms of monetary or status gains and losses. In everyday interactions of this kind, therefore, subjects are not their full selves, but face each other as functionally delineated subjectivities. These subjectivities are rational within the constraints of their alignment with whatever social subsystemic imperatives they embody in any given situation (ibid.: 182). From this perspective, therefore, society consists of functionally differentiated regions in which citizens are constituted as subjects according to the functions they fulfill in an institutional architecture.

Habermas gives several specific examples in Legitimation Crisis. He identifies the economic system - capitalist in its structures, aligned according to individual profit motives (1975: 34) and class structures (ibid.: 37 sq.) - the administrative system, trying to maintain the macroeconomic environment of the former (ibid.: 34 ); the legitimation system maintaining the "basic bourgeois ideology of fair exchange," meritocracy and economic growth (ibid.: 36); and finally a sociocultural system in which the three aforementioned systems are represented to society as a whole (ibid.: 48). In each of these systems, actors actualize specific action orientations (the individual profit motive or the incentive of wage labor in the economic system, for example), and their individual actions are aligned according to specific steering media (money, law) with specific outcomes.

In any given situation, therefore, systemic imperatives work through "a nonnormative regulation of individual decisions that extends beyond the actors' consciousnesses” (Habermas 1989: 117). That is, a subject's actions and their outcomes are aligned by structuring perceptions of situations according to the medium of whatever subsystem the subjects find themselves actualizing.

However, for every participant in any given situation, another perspective is possible: "the teleological aspect of realizing one's aims (or carrying out one's plan of action)" can be distinguished from "the communicative aspect of interpreting a situation and arriving at some agreement" (Habermas 1989: 126). The result of the former aspect of a subject's action orientation is success according to the subsystemic imperative; the result of the latter is a consensus evaluating the interaction according to normative standards (ibid.: 127). However, emphasis must be put here on the dissimilarity of the systemic and the lifeworld orientation of these participants. Interactions, when aligned by a systemic medium (money, or legal technique), are structured to arrive at a purely functional goal which is predetermined by the medium of interaction (ibid.: 150). Thus, the ends of the interaction are given, and the interaction itself is subject to a means-ends-rationality. An example for this are capitalist market transactions, subject to monetarily mediated maximization motives. However, each participant in a capitalist market transaction also has the capacity, at any point, to assess the monetary medium of the interaction the participant finds herself in based 
on a questioning of the ends the medium prescribes. This allows the possibility to change the medium of successful interaction: any sale can be turned into a gift at any point.

Thus, in every interaction, there is always a possible perspective on the interaction which is radically dissimilar to its functional means-ends alignment (Habermas 1989: 150). The gift in this example, however, is not a different medium (leading, with Bourdieu, from a market transaction to a symbolic economy), but a possibility contained within the market exchange itself. As Habermas argues, the success- or goal-oriented actions of subjects acting in the context of their subsystemic imperatives are open to scrutiny based on the normative assessment of situations by these subjects in the same situation. The assessment can be negative or positive - the market exchange can be endorsed or criticized - but in any given situation, there will be a normative standard applied to it which is dissimilar to the situation itself. Habermas (ibid.: 137) argues that the normative standards played out in such assessments are derived from the intersubjectively achieved by the communicative consensus of the participants in a situation. Any subjectivity or action orientation of a social subsystem must justify itself normatively against this communicative consensus. What enables this justification, and by the same token what makes it necessary, is the lifeworld. The lifeworld perspective is the implicit horizon accompanying the act with which a subject positions herself in a communicative interaction (ibid.: 135). Thus, a subject may position herself as a wage worker, while simultaneously questioning that same position based on her normative reflections, contained in and derived from her subjective horizon: her lifeworld.

In any everyday situation where communicative interaction takes place, "the lifeworld appears as a reservoir of taken-for-granted, of unshaken convictions that participants in communication draw upon in cooperative processes of interpretation" (Habermas 1989: 124). Thus, according to Habermas, all social interactions, even those which are organized according to systemic media like money, are rooted in subjects' lifeworlds. Lifeworlds are intersubjective and diverse, however; they form the cultural, political, and broader social background for any given interpretation of any given social situation by a subject in this situation (ibid.: 131). For any of these interactions, then, a subject is free to juxtapose different and varying interpretations: it may engage in a market transaction endorsing the goals and media used in such a situation; it may do so without endorsing them; or it may abstain from using the monetary medium and turn the transaction into a gift. Thus, even when the subject engages in the market exchange, the possibility of turning it into a different type of interaction is always present because the subject is capable of juxtaposing different interpretations of the situation, and hence change both its individual action orientation and the socially aligned outcomes (ibid.: 120, cf. ibid.: 180). Nevertheless, the juxtaposition of different normative backgrounds by subjects, according to Habermas, is not licentious: it remains within the normative horizon of the society in question at any given time (ibid.: 119). Consequently, it is possible that the horizon of a society closes into the point that communicative strategies based on systemic media dominate normative assessments; a society can become pre-Modern, or capitalist.

Participants in a social situation constantly evaluate the normative content of the situation together with their fellow participants based on their reservoir of previous experiences, previous normative judgments, and accumulated normative convictions (Habermas 1989: 140). The irreducible crux of this argument, as said above, is the radical dissimilarity of lifeworld and systemic perspective. What is the condition of possibility for this radical dissimilarity?

It has been said above that the normative assessment of a situation is made possible by a communicative excess inherent in each situation insofar as it allows subjects to freely juxtapose their interpretations of the situation at hand. To the extent that this ability to juxtapose is not licentious, but oriented towards an intersubjective horizon of consensus, two possible origins arise. On the one hand, Habermas argues that the language spoken when normatively assessing social facts is different from that aligned with systemic mediation: it alone is a transparent, horizontal, and fully democratic form of communication (cf. Habermas 1989: 140 sq.). The possibility of such a form of communication has long been disputed (cf., for example, Lyotard 1984: 65 sq.). This does not jeopardize Habermas's argument, however, since the dissimilarity of normative assessments with other communicative interactions does not stem from a structurally separated lifeworld perspective. Rather, the perspective is contained in a situation, but excessive relative to its systemically aligned strategies: while normative assessments as such are always intersubjective, and thus their existence is dependent on the possibility of transparent communication (Habermas 1989: 124), the lifeworld of each participant is not itself a subsystem and thus not dependent on a specific form of linguistic mediation. Rather, it is the site in which each subsystemic mediation comes to be transformed into meaningful action - and therefore also the site in which social meaning exceeds the mere execution of the subsystemic imperative (ibid.: 133). 
Therefore, the second element constituting the possibility of a lifeworld orientation radically dissimilar to systemic orientations is its status as a background informing normative judgments: it is, as Habermas argues, a "taken-for-granted background" that always remains below "the threshold to basically criticizable convictions" (Habermas 1989: 131). While a subject assumes a position in a systemically mediated social interaction consciously, and thus more or less consciously plays a role, the lifeworld remains an ever-present potential, a remainder or excess beyond any given situation that, if actualized in speech acts, allows the normative scrutiny of the situation.

Hence, Habermas argues that individuals interact with one another as doubly mediated subjectivities. On the one hand, they are constituted by the subsystemic functions as which they face one another. On the other hand, outside of their functions, subjects individually and collectively question the legitimation of these functions and the subsystems they stem from. Both of these facets of everyday subjectivity are rooted in the subject's lifeworld. Because that is the case, the latter encompasses the former at all times. Consequently, in an ideal social environment, all systemic orientations would constantly be under scrutiny, and would be adjusted as the communicative consensus of the citizens' lifeworld would demand (Habermas 1989: 137). This is not the case, however. Under conditions of social normality as defined by the society's subsystems - especially the economic one - normative questioning on a total social scale is, as Habermas points out, exclusively a paid profession (ibid.: 155). Under conditions of crisis, nonetheless, one would - and Habermas does - expect a spread of normative unease from the ivory towers of professional critique to the lifeworlds of average citizens. Thus, it is necessary to see how the transposition of systemic and lifeworld perspectives plays out when the systemic alignments of subjects, and especially the alignment derived from imperatives of capitalist accumulation, starts to fail.

\section{Crisis: Systemic Underperformance, Normative Potential}

Given the duality of systemic and lifeworld perspectives on any social interaction, it is not surprising that the central point of Habermas's argument in Legitimation Crisis is the transposition from the objectively problematic character of social conditions - empty homes and homeless people - to their normative problematization - the moral or political assessment of the housing market. From the perspective of the capitalist market subsystem, the coexistence of empty homes and homeless people is a mere fact. Neither the monetary medium nor the profitmaximizing goal of capitalist market interactions allow a normative judgment of empty homes and homeless people in their coexistence. To arrive at a normative judgment, then, intersubjective questioning must intervene.

The fundamental type of crisis in advanced industrial societies, according to Habermas (1975: 45), is the economic crisis. Given that, as outlined above, all social phenomena have systemic and normative dimensions in Habermas's framework, it should be expected that such systemic crises of economic performance are intimately related to normative scrutiny of the economic system which made them possible: crises of legitimation and motivation, economic crises, and crises of rationality (ibid.: 45 sq.).

For Habermas, an economic crisis can occur, first, as a crisis internal to the monetary medium, resulting from the tendency of the rate of profit to fall - i.e., the contradiction between the social character of capitalist accumulation and the private character of the appropriation of its benefits (Habermas 1975: 51 sq.). Secondly and related, it can manifest a form of class struggle, when the payment of low wages clashes with the necessity of effective demand (ibid.: 57). The state, Habermas argues, has to sustain the irrational structure of private allocations of public surplus and public infrastructure investments without ultimately threatening the private mode of accumulation that created the misallocations in the first place (ibid.: 52 sqq.). This leads to crises of rationality in its steering capacities and outcomes.

More importantly, crises of this kind put pressure on the state for sustaining the capitalist system under the conditions of the increasing public realization that it violates its own supposedly universal ethical standards (Habermas 1975: 59). The more pressure the economic subsystem puts on the state to serve its fundamentally irrational capitalist allocation structures, the more problematic it gets for the state to sustain its own legitimation (ibid.: 48). One would expect that this holds especially in a time when states bail out banks while ignoring the poverty of an increasing part of their citizenry (Stiglitz 2006: 251). However the state's legitimation crisis remains subsequent and secondary to the underlying crisis of economic (ir)rationality.

Since Habermas's ontology of institutions identifies them as communicative acts of systemically mediated subjects (1989: 150), a legitimation crisis of a social subsystem induces a motivation crisis on the individual level (Habermas 
1975: 76). For subjects constituted as economic individuals, capitalism's behavior of violating the ideological fictions of meritocratic allocation as well as their expectations of either equitably distributed or quantitatively growing outcomes (or both) increasingly jeopardize their allegiance to the wage labor system (ibid.: 75). Since this lack of individual motivation results, for Habermas, from an intersubjective normative assessment of capitalist institutions, it should translate to a collective lack of support for said institutions seamlessly. As Douglas Kellner (1992: 198) points out, Habermas argues that "the system must provide legitimation and motivation in order to continue functioning," because a crisis of legitimation and motivation may lead to individuals "calling into question at least some aspects of the capitalist system and instigating a demand for social transformation" (ibid.: 199).

The transposition of capitalism's crises to the total systemic crises that Habermas argues for (1975: 3) is exacerbated by the specific conditions under which the crisis phenomenon occurs. The social differentiation of Modernity, leading away from a domination by the more or less unquestioned authority of the religious subsystem, makes individuals' allegiance to capitalist societies increasingly dependent on the performance of the capitalist system, rather than a transcendent standard (Habermas 1989: 169). In the development towards Modernity's rationality, the lifeworld's excess over systemic imperatives which allowed the normative questioning of the latter is no longer rooted in a separate faith-based subsystem, but is now derived from the subject's communicative intersubjectivity (ibid.: 142-145). Thus, economic crises and misallocations have palpable social ramifications against which capitalism must justify its continued existence before the court of public opinion (Habermas 1975: 10).

The cultural subsystem can respond to this with two possible justifications. On the one hand, it can attempt to legitimize the capitalist mode of production by highlighting its actual or potential growth. Such attempts are repeated in almost every crisis. Arguments of the form of 'you never had it so good, however, are neither new nor very effective against the backdrop that the current capitalist economy has only grown substantially in one sector credit and financialization - since the late 1970s (Galbraith 2012: 148). This growth has not spread to other sectors of the U.S. (or European) economies (ibid.: 144); and it has furthermore been restricted to the top few percent of either economy (Stiglitz 2006: 67). Growth can therefore hardly be a successful strategy of justifying capitalism in the face of recent crises. Since crises, as Habermas (1975: 30) argues, function as "practical critique of the ideology" of growth theorems, capitalist exchange relations must be legitimated by means of the fiction of just exchange relations. However, this fiction can scarcely be upheld (among a wealth of literature supporting this claim, see Stiglitz 2006; Rodrik 2011; or Galbraith 2012).

One may conclude: while in late capitalist societies, legitimation can conceivably be delivered by cultural sectors of society (adding stability), but, more importantly, it must be delivered (adding crisis potential). If legitimation is missing, a crisis of capitalism may become so severe that its entire social and institutional edifice comes under scrutiny (Kellner 2012: 56).

Obviously, the question of a socio-economic system's legitimation only arises when that system is structured democratically, i.e., with a reasonable amount of possible public questioning and discussion. Thus, even a merely formally open democracy allowing a formal freedom of speech, which several of the advanced industrialized democracies currently appear to approach (Luke 2012: 31), ideally puts additional pressure on systemic imperatives to justify themselves (Habermas 1975: 36). The operative word, however, appears to be ideally, given the framing power of media and their consequent ability to persuade the public that there is not, in fact, a lack of legitimation of capitalism and/or its state system even when (especially when) there should be according to Habermas's model.

Thus, as Habermas (1975: 4) argues, a crisis does not occur every time a social shift takes place. Objective social problems also have to be subjectively perceived as such: as structurally problematic to the objective sustenance of, and subjective social identity within, the total socio-economic system. This suggests the necessity of media and otherwise mediated discourses to make citizens aware of structurally problematic developments (ibid.: 37). The role of critical media would then be to allow intersubjective normative assessments by providing the necessary resources for lifeworlds to connect. Were one to argue, therefore, that the normative excess contained in the lifeworld perspective still persists, this would be an opportune place for a media critique. This is the argument Habermas himself makes. Habermas's "structurally depoliticized public realm" (ibid.: 37), could then be seen as a precursor to the current depoliticized media environment (cf. Brown 2005: 48). The next step in this argument would be to note that the transposition of economic systemic crises to normative legitimation crises is obstructed all too effectively by contemporary Western media (Luke 2012: 22; for Germany, this has been argued by Habermas 2012: 136). Examples include the proliferation of right-wing political obstructionism in the United States (Fraser 2012: 168), the silencing of Occupy by all means (cf., for example, Nagourney 2012), or the all-too-willing suppression of economists who 
might suggest that the current short-term solutions used in the European Sovereign Debt Crisis might not be altogether desirable (such as Paul Krugman).

This argument, however, is not that of this paper. On the contrary: such media criticism still suggests that a form of public accountability could possibly persist, were the media system structured differently (cf. Luke 2012: 22). Outlets like 'Democracy Now!' would then serve as examples for attempts to tap into some kind of resource for resistance politics. The simultaneous diagnosis of an existence of such programs and widespread political passivity or even complacency does not fit well with this kind of media criticism. One must therefore take a closer look: the problem seems to affect more than just the surface of contemporary media.

\section{Neoliberalism}

To show this, consider for example the application of the Habermasian (1975: 2) conception of an economic crisis to the European Sovereign Debt Crisis:"[C]rises arise when the structure of a social system allows fewer possibilities for problem solving than are necessary for the continued existence of the system." On a global scale, it has been argued several times that curbing financial flows is necessary for a sustainable growth of industrial production circuits (cf. LiPuma and Lee 2004; Rodrik 2011). That states appear to be unable to follow this advice, in turn, has been identified as a collective action problem in the absence of an international hegemon - ironically, deregulation has been identified by those who advance this criticism as the last hegemonic act of the United States, which was strong enough for deregulation, but not for re-regulation (Cerny 1994: 241; cf. Arrighi 2012). In Europe, likewise, problems posed by the international embeddedness of European sovereign debt (Lane 2012: 50) appear to be hardly solvable in an institutional structure that oscillates between technocratic non-deliberation (Habermas 2012: IX) and attempts at consensus politics often stifled by the interests either of the City of London (Shipman 2012) or national(ist) political constraints (Weisenthal 2011).

In other words, the European sovereign debt crisis should have presented an excellent political opportunity for the practical critique of ideology of capitalist economy and state alike (Habermas 1975: 30), given the simultaneous impoverishment of large masses of European citizens and incapacity of free-market ideology to cover up financial and industrial markets' inability to sustain themselves (Lucarelli 2011; Krugman 2012). Habermas (2012: 4) has argued forcefully that such a legitimation crisis is imminent. Curiously, however, he argues for a reform of European (and global) structures of governance given the capitalist economy and its financial architecture (ibid.: 3, 5, 7, and 112). For example, a practical critique of capitalist ideology seems to allow a normative criticism of "[t]he neoliberal assumption that commercial banks and their interbank markets are more efficient at evaluating financial risks than central banks" as such, and not only of the fact that this assumption "informed the original design of the Maastricht Treaty" (both from Lucarelli 2011: 215). Yet, curiously, Habermas (2012: 5) makes only the latter critique his central claim. Likewise, one would think that arguments for prioritizing the recapitalization of financial institutions over socially necessary programs (Lane 2012: 59) are only legitimate within a framework taking the necessity and priority of these institutions - and hence of their corresponding economic medium over social concerns - for granted. Here, too, Habermas considers this prioritization merely as a given condition under which the actual goal of his essay, the reform of the European Union, has to be pursued.[1]

These failures of a transposition of systemic crises of economic performance to a normative questioning of capitalism, along with the curious fate of American reform proposals, floated to great fanfare immediately after 2008, and retracted shortly thereafter, seem to indicate a crisis of the transposition mechanism. Partly, it can certainly be argued, the failure of U.S. reform proposals is due to the obstructionism currently holding Washington, D.C. in its grip. Partly, however, as pointed out above regarding a critique of media, the problem runs deeper: a critique of obstructionism, like a critique of media, presupposes that a form of public accountability could possibly persist, were the political system structured differently. I argue, however, that in Europe and the United States, the capitalist economic system does not suffer from a legitimation crisis despite being in an economic crisis. Consequently, it does not need to justify itself in order to maintain its citizen's allegiance. Its normative justification before the court of public opinion, which Habermas (1975: 43) had deemed crucial, has been replaced with a hollowed-out normativity largely identical with cynicism (Brown 2005: 43) - and the precariousness of employment which leaves no time for political activity (Boltanski and Chiapello 2005: 184), or actively discourages it in the grip of a more pervasive security apparatus (Harvey 2005: 77). 
Habermas's argument for achieving a normative critique of objectively problematic socio-economic conditions of 'crisis' depends on the assumption of a lifeworld perspective which, as outlined above, can be identified as dissimilar to systemic communicative media (1989: 122). This assumption, I argue, must now be questioned. The phenomenon Habermas described with his concept of a lifeworld perspective presupposes at least three elements which have been systematically altered during the process of social, political, economic and cultural changes widely known as 'neoliberalism': 1. the objective necessity of legitimation; 2. the subjective possibility of a legitimizing or delegitimizing assessment of systemic action alignments; and 3. the possibility of an intersubjective normativity in general. In what follows, each of these three components' restructuring and subsequent disappearance through the relevant policies of the neoliberal project will be analyzed.

\section{Concerning the Objective Necessity of Legitimation}

As Habermas (1989: 137) had argued, every subsystem is in need of legitimation insofar as it is only actualized in a communicatively established and maintained situation, and thus beholden to an intersubjective, normative assessment of the situation. I argue, however, that the ability of subjects in advanced industrial societies to perceive an economic crisis as a crisis of the legitimation of capitalism, and consequently the state's attempts to restore the capitalist economy, has come to be severely threatened.

The prioritization of financial recapitalization over social measurements, and hence the legitimation of the state in sustaining the economic system is posed either exclusively, or with much greater publicity than the corresponding question of the legitimation of that economic system itself. Thus, the legitimation of the state, were it at stake in a public normative deliberation, would be threatened, mirroring the crisis of the legitimation of its underlying economic system. This, however, presupposes that a normative view on the state exists which recognizes its functions as more than merely sustaining economic accumulation. For Habermas (1975: 23), the state's legitimation in maintaining the capitalist economy was directed towards securing a basic equality of outcomes on the one hand, stability of macroeconomic situations on the other. As Wendy Brown suggests, however, this function of the state has changed in neoliberalism. "The state openly responds to needs of the market, whether through monetary and fiscal policy" policies which Habermas's assessment would have recognized as well - but also "immigration policy, the treatment of criminals, or the structure of public education" (2005: 41).

Thus, not only have the functions of the state shifted away from the social security model Habermas (1975: 38 sq.) had diagnosed, but, the state has become structurally unable - and more importantly: structurally unwilling - to maintain social security and equitable market outcomes as desirable goals.[2] As Brown argues: "Rather, neoliberal rationality extended to the state itself indexes the state's success according to its ability to sustain and foster the market and ties state legitimacy to such success" (2005: 41; cf. Harvey 2005: 80). In other words: rather than maintaining its political capacities in trying to achieve a more socially equitable outcome, more ecologically sustainable conditions, and stable macroeconomic alignments against capitalist principles of accumulation (Habermas 1975: 34), the state now secures the struggle of an upper class against a lower class (Harvey 2011: 261; cf. Cerny 1994). "In doing so, the state is no longer encumbered by the danger of incurring the legitimation deficits predicted by 1970s social theorists" like Habermas (Brown 2005: 41). From this perspective, the above list of supposedly 'inevitable' short-term solutions to the European Sovereign Debt Crisis makes perfect sense: a neoliberal state is structurally unable, for example, to nationalize banks (Harvey 2005: 73).

Moreover, its legitimation cannot suffer from its inability to do so. This leads from the secondary issue of an absence of a crisis of state legitimation to the primary issue of an absence of a legitimation crisis of capitalism itself. Even those citizens whose ability to submit action orientations of elected officials to normative scrutiny remains intact amidst a depoliticized media have no means to meaningfully do so other than under the assumption of the inevitability of capitalism. One reason for this is that, as Brown (2005: 53) shows, that the lack of alternatives of liberal capitalism is all too real for most people. In the absence of an alternative to business-as-usual politics - i.e., in the absence of a meaningful alternative on the Left of the North American and European political spectrum that is not immediately suppressed or discredited - citizens can only choose between the merely formal alternatives of a party system in which an overarching imperative holds sway: "a governmentality of neoliberalism that eviscerates nonmarket morality and thus erodes the root of democracy in principle at the same time that it raises the status of profit and expediency as the criteria for policy making” (Brown 2005: 52; cf. Kellner 2012: 47). 


\section{| Concerning the Subjective Possibility of Legitimation}

For the second reason, one needs to go further. Up to this point, the problem can still be framed in terms of a Habermasian critique. Thus, the foregoing reconstruction of Brown's argument may have led to the suspicion that the neoliberal project is a repressive project: the violent imposition of a neoconservative free-market ideology[3] on unsuspecting populations by means of undemocratic institutions (such as the Mont Pelerin Society) and their influence on elected officials (de Angelis 2005: 251). This diagnosis is undoubtedly true for a large part of the neoliberal project: in both Chile and China, an autocratic government restructured the state, with help from outside "experts," such that it shed its last traces of social responsibility, pitted the population against one another as atomistic individuals, and kept them in check by means of police forces (Harvey 2005: 130).

Habermas's conception would cover this: neoliberalism would be the violent imposition of a specific subsystem's rules on subjects' conduct, a narrowing of the lifeworlds of individuals with an economic imperative. Subjects' lifeworld-perspectives on systemic imperatives would be narrowed, though they could not be replaced, since they remain as intersubjective sites of normative judgment. Neoliberal governance would consequently have to be seen as similar to the bureaucratization of a subjects' conduct that Habermas had identified in the political technology of the welfare state. By supporting a subject with welfare payments, a welfare regime has to constitute this subject as an individual whose needs are reduced to a juridical classification of necessary and superfluous needs, and whose life is quantified economically in the process (Habermas 1989: 361). Neoliberal practices replace, a Habermasian could argue, the content of this imposition, but not its form. Thus, a citizen is no longer individualized by a bureaucracy molding her as a welfare recipient - but she is individualized by a bureaucracy molding her as a rational-economic utility maximizer (workfare instead of welfare). Furthermore, she is juridified by reducing her collective rights to individual rights. This goes hand in hand with a formalization of concepts of equality. When an individual is presumed to be fully emancipated when formally equal before the law, but no attempts are made to make her actually capable of exercising this equality, her freedoms are jeopardized, and states become repressive (Harvey 2005: 81).

One could infer from this repressive status of the economic re-shaping of society in neoliberalism that it, too, has to presuppose - to respect - a certain grounding of a citizen's capacity to normatively assess what she is subjected to. This capacity would be derived from a lifeworld perspective which cannot fully be transformed by repressive governance because the lifeworld perspective is structurally dissimilar to the systemically mediated communicative routines repressive governance would implement. Habermas's theory would be partly vindicated.

This repressive hypothesis is misguided, however: neoliberalism goes much deeper. It is, as Brown (2005: 38) notes, a project whose supreme purpose is the re-structuring of subjectivities. It is a form of governmentality (cf. Lemke 2011). Governmentality, a term coined by Foucault, describes the combined usage of macropolitics - the imposition of a neoconservative free-market agenda by means of a state - and micropolitics: "powers that operate on the body and psyche in local and often non-obvious fashion" (Brown 2005: 72). The latter is especially insidious because it does not follow the repressive logic outlined above: rather, it entails "the directing and channeling of the behavior of the body individual, the body social, and the body politics by means other than force or even explicit rule" (ibid.: 73). Specifically, in the neoliberal project, "the extension of economic rationality to formerly noneconomic domains and institutions reaches individual conduct, or, more precisely, prescribes the citizen-subject of a neoliberal order" (ibid.: 42; cf. Bauman 2000). The neoliberal subject is configured in such a way that she subjects herself - voluntarily - to the imperatives of the economic subsystem (Wolin 2008: 239).

In Habermas's model, then, one would have to conclude that neoliberal governmentality produces the subjective element in which all subsystemic imperatives come to be exercised and simultaneously assessed: the lifeworld. If the lifeworld, as Habermas had argued, is to be seen as a reservoir of self-evidently given, unquestioned normative statements and assessments, neoliberalism can be formulated as a project of shaping intersubjective communication such that the reservoir to judge and assess any given situation no longer contains normative standards which are not already economic (cf. Sennett 1998). A neoliberal citizen cannot assess the normative validity of a subsystemic imperative other than from a specifically shaped position - as a possessive, atomistic, gender-neutral (which is to say: male) individual; a rational, egoistic utility-maximizer. Thus, in the above example, the citizen constituted as an individual who is formally equal before the law with her richer compatriots, but not actually able to afford justice, would not even be capable of recognizing this as an injustice were the neoliberal project fully developed. The judicial system would retain its full legitimacy despite not actually delivering equal justice before the law.

Fully developed, then, the neoliberal project would not be repressive because it would not need to be repressive. 
It would not need to legitimize itself because its normativity is already identical to the reservoir of possible normative judgments any subject (i.e., individual) has at its disposal in any given situation. A fully subjectified neoliberal citizen will not be able to distinguish between the normal functioning of a capitalist economy and its crisis situations. As Habermas (1975: 3) had argued, an economic underperformance is only identifiable as a crisis if it subjectively perceived as such. Habermas explicitly (ibid.: 23) traces the ability to perform this identification back to the autonomy of the intersubjectively constituted reservoir of normative judgments given as lifeworld. If this reservoir, however, is restructured such that its contents are derived from the same subsystemic (economic) imperatives as that which it judges, citizens - atomized individuals - will not be able to experience structural changes as threats to their socially constituted identities.[4]

This is not the full picture, of course. On the contrary: the existence of very real, very widespread discontent and unrest signal that citizens' lifeworlds are not completely shaped and molded by neoliberal imperatives - that, even now, remnants of traditional normative judgments remain, as Habermas (1975: 80; cf. Habermas 2012: 49) had predicted. Examples include the Alter-globalization movements of the early 2000s, as well as Occupy since 2011. Would the contemporary Western media system really have to spend so much time and energy on suppressing the mediated representation of rebellion if rebellion were always already captivated by neoliberal economizations?

On a theoretical level, then, this could indicate that Habermas's perspective may still be partly right in arguing for the normative potential of lifeworlds. They may be produced by neoliberal practices on the individual level, but perhaps there is potential in their intersubjective constitution? Habermas (1989: 120) had argued, after all, that normative judgments are never just at an individual's disposal, but rather established out of every situation intersubjectively through speech acts: situation, subjectivities, and lifeworld horizons originate at the same time, and change with every communicative realignment in the situation. Perhaps the capacity to assess normative implications intersubjectively is what underlies the critical potential referenced above?

\section{Concerning the Possibility of an Intersubjective Normativity}

This critical potential is not, however, actualized as widespread action. The reason for this lies in the structure of the restructured lifeworld of neoliberal subjects. In turning citizens into atomistic individuals, neoliberal policies have removed the very possibility of communicatively established intersubjectivity, and thus normative judgments in general (Habermas 1989: 124). Individuals can no longer establish a communicative consensus outside of being already aligned along the imperatives of capitalist rationality. This can partly be seen in terms of the previous discussion: a large part of social movements whose goal is the change of global(ized) capitalist relations nevertheless voice demands that remain within the boundaries of a capitalist economy - despite the often invoked rhetoric of capitalism's obsolescence. An example is the World Social Forum, whose central demands, while including a global redistribution of wealth towards reaching the Millennium Development Goals, nevertheless take large parts of the global capitalist economy for granted.[5]

Since such organizations have to communicate with states and market actors, however, taking capitalism for granted could also, of course, be strategic. Much more instructive, then, is a look at the Occupy movement. Started as Occupy Wall Street in New York, it has since spread over the world, uniting 900 cities for a global rally in October 2011. It is not, however, these admirable achievements that are relevant here - for their effects, as has been noted from different normative perspectives (Stiglitz 2006; Harvey 2011; Dean 2012: Ch. 6), are limited at best - but rather the attempts of the movement to infuse its surrounding societies, and particularly the American one, with the potential to form a consistent and ongoing normative critique. In other words: one of the goals of Occupy is to build a lifeworld of intersubjective critique. This is evident in activist Eli Schmitt's (2011: 3) statement: "Someone asked what the action was, what we were going to do, and someone else responded that this was the action, that we were there to talk and organize." Another indicator is Marina Sitrin's (2011: 4) comment: "Most of us believe that what is most important is to open space for conversations-for democracy-real, direct, and participatory democracy. Our only demand then would be to be left alone in our plazas, parks, schools, workplaces, and neighborhoods so as to meet one another, reflect together and in assembly forms decide what our alternatives are." This, however, is not only symptomatic for the widespread conviction among occupiers that a new society and a new democracy were born. It is also symptomatic for the merely formal character of the central demand of Occupy (in most, if not all, of its incarnations): as soon as Occupy abandoned demands that, while certainly worthwhile, remained within the 
capitalist economy - such as demands for the reintroduction of the Glass-Steagall Act - it became a mere call for horizontality as an organizing principle. That is, rather than making the establishment of a democratic public sphere (which is to say an intersubjective lifeworld, allowing a capability of normative assessments of social institutions) a means towards a thorough and radical social critique, Occupy remained on the formal level, and with increasing desperation, made an end out of creating a lifeworld for normative judgments (Harcourt 2012). I do not, however, want to argue for a condemnation of Occupy based on these grounds, as others (e.g., Dean 2012: Ch. 6) have done. It is hard to imagine that the normative question raised, though not answered by movements like Attac or Occupy is not transposed at least into widespread demotivation. What might explain the desperate state of the task of establishing normative demands that are not already part of the capitalist economy - or to establish an intersubjective lifeworld in general?

I suggest a third origin of the problem, that runs even deeper than the previous two. Part of neoliberal subjectivity, as has often been argued, is a radical individualism (Bröckling 2003: 22; Wolin 2008: 112; Gershon 2011: 538). For neoliberally molded individuals, an ethical imperative exists "to provide for their own needs and service their own ambitions," bearing "full responsibility for [their] action[s] no matter how severe the constraints of this action" (Brown 2005: 42). The neoliberal subject is constantly worn out by facing social obstacles as if they were natural (Sennett 1998: 130 sqq.), and more importantly, as if it were the subject's responsibility to remove them, or to fail (ibid.: 84 sqq.). The demands a neoliberal individual faces are insurmountable and exercise permanent pressure (Brown 2005: 20) - while the individual is, at the same time, left to face them alone, unable to come to a normative conclusion on whether they might be legitimate or not.

Thus, a legitimation crisis need no longer be associated with a motivation crisis and its corresponding potential to spread. A neoliberal subject does not need to be motivated: it is presumed - and thus forced - to be motivated to overcome all obstacles all by itself (Brown 2005: 22 and 25). Moreover, if it fails, it is always already infused with the inability to perceive this failure other than as its own personal failure, and it is driven by the will to overcome what it cannot perceive other than as its own weakness (ibid.: 16). Likewise, the terms of perceiving such failure are themselves economic and radically individualist: a lack of individual skills, capacities, and dexterity (McQuaid and Lindsay 2005). The neoliberal individual is permanently worn out and unable to develop the necessary perspective to perceive this as an onslaught on its well-being - which, according to Habermas's (1975: 43) diagnosis, would lead its motivation to vanish, and might lead it to question the normative validity of its social system.

Motivation is thus replaced by precariousness (Wolin 2008: 239). Subjects do not perform their tasks because they feel motivated for them, but because they are constantly pressured to perceive themselves as nothing but fulfilling the task (Bröckling 2003: 12). The neoliberal subject, as Boltanski and Chiapello (2005: 169) argue, is beholden to the general standards of 'project orientation' where

the general standard, with respect to which all persons' and things' greatness is evaluated, is activity...Life is conceived as a series of projects ... [w] hat is relevant is to be always pursuing some sort of activity, never to be without a project, without ideas, to be always looking forward to, and preparing for, something along with other persons whose encounter is the result of being always driven by the impulse of activity.

This activity, however, hardly contributes to an intersubjectivity which might add up to an intersubjective lifeworld. The first and perhaps most important constraint is the mode of perceiving other people from an individualized, project-oriented vantage point: they are always competitors, or, at best, temporary team members, but never equal participants in the assessment of the situation (Bröckling 2003: 21). The potential for an intersubjective assessment of a situation is at least severely truncated by this hostile - in Habermas's (1989: 117) terms: strategic - relation of individuals to one another.

Even if they were to cooperate, however, cooperation will frequently be of a merely technical nature, and directed towards the success of every project. Boltanski and Chiapello's (2005: 169) analysis, while suggesting that individuals are adaptable - which could conceivably mean: tactically savvy in a possible strategy of perruque or everyday resistance tactics (de Certeau 1984) - also highlights that individual's adaptability and success is always measured within the project and by a superior. Subjects are economically potent and politically docile (Foucault 1995). Both conditions, especially when measurement is applied constantly and punishments are severe, preclude a normative judgment on the project as a whole (Boltanski and Chiapello 2005: 182).

Finally, projects are short-lived and precarious, depending on technological alignments (subject to accelerating rates of improvement or at least re-branding), performance standards (subject to change, if not constant change), minimal contract durations (shifting team memberships and working atmospheres), and other, more or less arbitrary 
shifts and changes. An individual must adapt, which means it must always be ahead of itself - ahead of the situation, ready to realign and adapt, and to shed its contacts with its competitors which may become and cease to be team members in short spans of time (Bröckling 2003: 21; cf. also Pérez 2010; as well as the classical analysis by Schumpeter 1950).

A lifeworld, Habermas argued, requires experiences and formative judgments - in other words, it requires time and dedication to normative assessment. How is an individual to develop the ability to form and maintain a reservoir of normative orientation under conditions in which "the temporary contract is in practice supplanting permanent institutions in the professional, emotional, sexual, cultural, family, and international domains, as well as in political affairs"? (Lyotard 1984: 66)

\section{| Conclusion}

In both cases, systemic imperatives - and especially the imperatives of what Habermas had identified as the economic subsystem - appear to have assimilated citizens' lifeworlds. A neoliberal subjectivity does not have a reservoir of possible communicatively sustained normative judgments to apply to its own and others' behavior which are not already aligned with the imperatives of the economic subsystem. Within Habermas's framework, one would thus have to conclude that the lifeworld has become what Habermas had explicitly argued it cannot become: a subsystem. This would mean that it has lost its position as implicit background or horizon - informing subjects, but not directly at their disposal in social situations (Habermas 1989: 123) - and became something directly manipulated by subsystemic imperatives. The latter, however, is not possible within Habermas's conceptualization of subsystemic imperatives as distinct from the social integration achieved by normative consensus (ibid.: 154). Were the lifeworld replaced by a subsystem attempting to functionally emulate it, the latter would have to be a subsystem producing normative judgments as direct systemic action orientations. This, however, would only be possible of a subject's normative judgments - which is to say, its entire behavior, all the way to unconscious judgments - could be programmed completely. How would such judgments be normative, however?

The neoliberal subject represents something far more insidious: a human being whose freedom is structured such that it subjects itself. Its ability to judge normatively is not impaired structurally, but in terms of content. The lifeworld of a neoliberal subject is not colonized by subsystemic imperatives in the sense that they have replaced the subject's ability to judge normatively. Rather, the subject is produced in such a way that its judgments, while remaining subjectively normative, cannot delegitimate the neoliberal capitalist apparatus of economic and political systems. The subject is in a permanent crisis of precariousness - but it is alone, and its normative judgments come to nothing. The capitalist economy is in a constant objective state of crisis - but it can endlessly reestablish itself as the only feasible alternative, thus precluding the subjective assessment which would turn a socio-economic crisis into an opportunity to call the socio-economic system into question.

\section{Endnotes}

1. Habermas (2012: 5) speaks of the "cunning of economic unreason" that brought the question of a reform of EU institutions to the political table.

2. This has recently been argued for Latin America by Jinkings and Guimaraes (2011).

3. Sheldon Wolin (2008: 137), argues that "[t]he socalled free market is not simply about buyers and sellers, or producers and owners, but about power relationships that are fundamental for the management of democracy."
4. A similar argument has been put forth by Heelas (1991) as well as McCabe (2003).

5. For a forceful description of what is nevertheless possible within these boundaries, see Cassen (2003). 


\section{References}

de Angelis, Massimo. 2005. "The Political Economy of Global Neoliberal Governance." Review (Fernand Braudel Center). 28,3: 229-257.

Arrighi,Giovanni. 2012. Adam Smith in Beijing: Lineages of the Twenty-First Century. London and New York: Verso.

Bauman, Zygmunt. 2000. Liquid Modernity. Cambridge: Polity Press.

Boltanski, Luc and Eve Chiapello. 2005. "The New Spirit of Capitalism." International Journal of Politics, Culture, and Society. 18,3-4: 161-188.

Bornstein, Avram. 2009. "N30 + 10: global civil society, a decade after the battle of Seattle." Dialectical Anthropology. 33,2: 97-108.

Bröckling, Ulrich. 2003. "Jeder könnte, aber nicht alle können" ("Everyone could, but not all can"), Mittelweg Journal for Sociology. 36,4: 6-26.

Brown, Wendy. 2005. Edgework: Critical Essays on Knowledge and Politics. Princeton: Princeton University Press.

Cassen, Bernard. 2003. "On the Attack." http://newleftreview. org/II/19/bernard-cassen-on-the-attack. Accessed November $30,2013$.

Cerny, Philipp. 1994. “The Infrastructure of the Infrastructure? Toward 'Embedded Financial Orthodoxy' in the International Political Economy." Pp. 223-249 in: Transcending the StateGlobal Divide. A Neostructuralist Agenda in International Relations, edited by R. Palan, B. Gills. Boulder and London: Lynne Riemer.

de Certeau, Michel. 1984. The Practice of Everyday Life. Berkeley: University of California Press.

Dean, Jodi. 2012. The Communist Horizon. London and New York: Verso.

Foucault, Michel. 1995. Discipline and Punish. NY: Vintage.

Fraser, Nancy. 2012. Interview. Pp. 155-172 in North American Critical Theory after Postmodernism, edited by P. Nickel. New York: Palgrave Macmillan.

Galbraith, James K. 2012. Inequality and Instability. Oxford and NY: Oxford University Press.

Gershon, Ilana. 2011. "Neoliberal Agency'” Current Anthropology. 52,4: 537-555.

Habermas, Jürgen. 1975. Legitimation Crisis. Boston: Beacon Press.

---. 1989. Theory of Communicative Action. Vol. II. Lifeworld and System: A Critique of Functionalist Reason. Boston: Beacon Press.
-.-. 2012. The Crisis of the European Union: A Response. Cambridge: Polity Press.

Harcourt, Bernard. 2012. "Political Disobedience." Critical Inquiry. 39,1: 33-55.

Harvey, David. A Brief History of Neoliberalism. Oxford and NY: Oxford University Press.

---. 2011. The Enigma of Capital. Oxford and NY: Oxford University Press.

Heelas, Paul. 1991. "Reforming the Self." Pp. 72-92 in Enterprise Culture, edited by R. Keat and N. Abercrombie. London and New York: Routledge.

Jinkings, Isabella and Vera Guimaraes. 2011. "The Neoliberal State and the Penalization of Misery." Latin American Perspectives. 38,5: 9-18.

Kellner, Douglas. 1992. Critical Theory, Marxism and Modernity. Baltimore: Johns Hopkins University Press.

---. 2012. Interview. Pp. $42-61$ in North American Critical Theory after Postmodernism, edited by P. Nickel. New York: Palgrave Macmillan.

Krugman, Paul. 2012. "Europe's Austerity Madness." http:// www.nytimes.com/2012/09/28/opinion/krugman-europes-austerity-madness.html. Accessed November 30, 2012.

Lane, Philip. 2012. "The European Sovereign Debt Crisis." Journal of Economic Perspectives. 26,3: 49-68.

Lemke, Thomas. 2011. Foucault, Governmentality, and Critique. Boulder: Paradigm.

LiPuma, Edward and Benjamin Lee. 2004. Financial Derivatives and the Globalization of Risk. Durham and London: Duke University Press.

Lucarelli, Bill. 2011. "German Neomercantilism and the European Sovereign Debt Crisis." Journal of Post Keynesian Economics. 34,2: 205-224.

Luke, Timothy W. 2012. Interview. Pp. 14-41 in North American Critical Theory after Postmodernism, edited by P. Nickel. New York: Palgrave Macmillan.

Lyotard, Jean-Francois. 1984. The Postmodern Condition: A Report on Knowledge. Minneapolis: University of Minnesota Press.

McCabe, Darren. 2003. "Individualisation at Work?" Organisation. 14,2: 243-267.

McQuaid, Ronald and Colin Lindsay. 2005. "The Concept of Employability.” Urban Studies. 42,2: 197-214.

Minsky, Hyman. 2008. Stabilizing an Unstable Economy. New York etc.: McGraw-Hill Publishing 2008. 
Mirowski, Philip. 2013. Never Let a Serious Crisis Go to Waste: How Neoliberalism Survived the Financial Meltdown. London and NY: Verso.

Nagourney, Adam. 2012. "Dissenting, or Seeking Shelter? Homeless Stake a Claim at Protests." http://www.nytimes. com/2011/11/01/us/dissenting-or-seeking-shelter-homelessstake-a-claim-at-protests.html?_r=0. Accessed November 30, 2013.

Pérez, Carlota. 2010. "Technological Revolutions and TechnoEconomic Paradigms." Cambridge Journal of Economics. 34,1: 185-202.

Reinhart, Carmen and Kenneth Rogoff. 2012. "Five Years After Crisis, No Normal Recovery." http://www.bloomberg.com/ news/2012-04-02/five-years-after-crisis-no-normal-recovery. html. Accessed November 30, 2013.

Rodrik, Dani. 2011. The Globalization Paradox. NY and London: W. W. Norton \& Co.

Schmitt, Eli. 2011. "Wanting Something." P. 3 in Occupy! Gazette, edited by A. Taylor, E. Schmitt et al.

Schumpeter, Joseph. 1950. Capitalism, Socialism and Democracy. NY: Harper.

Sennett, Richard. 1998. The Corrosion of Character: The Personal Consequences of Work in the New Capitalism. NY: W. W. Norton Co.

Shambaugh, Jay C. 2012. “The Euro's Three Crises.” Brookings Papers on Economic Activity. Spring 2012: 157-231.
Shipman, Tim. 2012. "New French leader fires a broadside at Britain: You only care about the City of London, says President Hollande." http://www.dailymail.co.uk/news/ article-2141040/Francois-Hollande-French-president-saysBritain-cares-City.html. Accessed November 30, 2013.

Sitrin, Marina. 2011. "One No! Many Yeses.” P. 4 in Occupy! Gazette, edited by A. Taylor, E. Schmitt et al.

Skidelsky, Robert. 2010. Keynes. The Return of the Master. NY: Public Affairs.

Stiglitz, Joseph. 2006. The Price of Inequality. NY and London: W. W. Norton Co.

Weisenthal, Joe. 2011. "Why German Taxpayers Should Be Forced To Bail Out Italians and Greeks." http://articles.businessinsider.com/2011-11-20/markets/30421346_1_german-banks-german-state-eurozone. Accessed November 30, 2013.

White, Stephen. 1980. "Reason and Authority in Habermas: A Critique of the Critics.” The American Political Science Review. 74, 4: 1007-1017.

Wolin, Sheldon. 2008. Democracy Incorporated: Managed Democracy and the Specter of Inverted Totalitarianism. Princeton: Princeton University Press. 